\title{
Performance Evaluation of Computer Simulated Extracted Features of Induction Motor with Healthy State of Insulation Present in Any Two-Phases
}

\author{
Amit J. Modak and H. P. Inamdar
}

\begin{abstract}
The state of degradation of stator groundwall insulation in induction motor results in the state of unbalance in three-phase stator current at fundamental frequency. In this investigation, the computer simulation model to determine this state of unbalance is developed. The practical assumption of stator winding of induction motor being star (Y) connected with isolated neutral is considered. On the basis of park's transformation model the stator current data in three-phase machine variable ('abc') form is first transformed into equivalent two-phase ('dq') form. The graphical dq-data pattern form is realized and certain mathematical parameters are extracted. The extracted features of induction motor for particular case of variation in the state of degradation of stator winding insulation are presented. The performance evaluation of the same is done. On the basis of performance evaluation, it is possible to determine the appropriate selection of specific input parameter conditions for optimal design of suitable artificial neural network classifier.
\end{abstract}

Index Terms-Computer simulation, induction motor, insulation degradation, park's current transformation, stator groundwall insulation

\section{BACKGRound of PRESENT ReSEARCH Work}

The state of stator winding insulation of induction motor is affected by the combination of thermal, mechanical and environmental stresses. The diagnostic tests and measurements to assess the condition of stator winding insulation in a particular machine are mainly classified in two broad categories viz., destructive tests and nondestructive tests. The destructive tests are the effective means to provide the direct measure of the status of insulation system. Another

Manuscript received November 22, 2011; revised February 29, 2012. The work presented in the research paper is part of $\mathrm{Ph}$. D. research work of first author. The associated $\mathrm{Ph}$. D. research work is in progress and registered by the first author under the guidance of second author at Shivaji University, Kolhapur, Maharashtra, India, since January 2008. The overall work is associated with the application of artificial intelligence (AI) based tool like artificial neural network (ANN) for the detection of state of unbalance of three-phase stator current data of three-phase induction motor used in continuous process industry. The application is in context to state of degradation of stator winding insulation of the respective phases. The present research paper only describes the modeling and simulation part of the state of degradation of stator winding insulation of three-phase induction motor under test.

Amit J. Modak is registered as a Ph. D. Research Student in Electrical Engineering at Walchand College of Engineering, Sangli, India with Shivaji University, Kolhapur, INDIA (e-mail: amitjmodak2000@yahoo.co.in).

H. P. Inamdar is working as a Research Professor in Electrical Engineering at Rajarambapu Institute of Technology, Rajaramnagar, District-Sangli, Maharashtra, INDIA and associated as research $\mathrm{Ph}$. D. guide with Shivaji University, Kolhapur, INDIA (e-mail: inamdar_hp@yahoo.co.in). more subjective means of assessing the insulation condition requires the dissection and examination of some sample of insulation. Both the above methods damage the winding and in turn make the machine unserviceable. The dc type of nondestructive test parameters are sensitive to dampness and contamination of a winding but are insensitive to the presence of voids and delamination. The dc type of nondestructive tests are useful to determine condition of any type of insulation if excessive moisture or major flaws such as cracks are present but as such are not effective to asses the condition of stator winding insulation subjected to ac stresses. This is particularly true in context of application of induction motors operating in variable speed drive environment. The ac type of nondestructive test parameters may be best indicators of remaining life under ac stress conditions but are considerably expensive to implement, particularly in context to low / medium capacity motors. Further, both the dc and ac type of nondestructive tests are useful to assess the remaining life of stator winding insulation when it is on the verge of failure. Both the type of test measures are as such relatively insensitive life indicators of stator winding insulation, which still have significant remaining life [1].

More or less the credibility in estimating the insulation condition under nondestructive tests must be correlated with the results of destructive tests [2], [3]. In the previous investigations it is ascertained that there is no correlation between the results of any nondestructive type of (dc/ac) assessment parameters with destructive type of (dc/ac/impulse) breakdown levels [1]. There is a need to establish an economical nondestructive test method for an assessment of state of degradation of stator groundwall insulation caused due to various factors in an integrated way. This is particularly true in case of large numbers of low / medium capacity induction motors operating in variable speed drive environment in any continuous process industry.

\section{SUGgested ApProAch With ThEORETICAL JUSTIFICATION}

In view of the above perspective, the present research work presents a novice nondestructive method to assess the state of degradation of stator winding insulation. The method is based on the concept that the degradation occurring in any one of the phases of stator winding insulation, effectively results in the state of unbalance in the three-phase stator current at fundamental supply frequency. The state of degradation of insulation, occurring on account of several reasons, in an integrated way can be readily represented in terms of magnitude and degree of unbalance in the stator current at 
fundamental supply frequency. The emphasis is towards the application of such unbalanced stator current numerical data to a suitable artificial intelligence (AI) based tool to determine the state of degradation of stator insulation. On experimental basis it is not feasible to collect the large set of unbalanced stator current data, which would model the entire range of state of degradation of insulation for the specific motor used in particular industry. However, in neural network based AI-technique, a large set of data pattern availability is required for the development of diagnostic model to detect the state of degradation of stator groundwall insulation. This is essential from the point of view of optimal design and efficient performance of the neural network classifier. Hence, there is need to generate large number of unbalanced stator current numerical data on the basis of computer simulation model to represent the various states of degradation of stator groundwall insulation occurring in respective phases. The formulation and execution of computer simulation model to generate unbalanced stator current data pattern was done in the previous work [4], [5]. In the previous work, the modeling was based on the assumption that the stator winding was star-connected with grounded neutral. As against this, in the present investigation, based on the similar approach, the formulation of computer simulation model is derived based on the practical condition of isolated neutral. The modeling is done for three-phase, cage-rotor, 10-HP, star (Y)-connected a c induction motor used in a continuous process industry.

In general, the motor is operating under the presence of many internal and external recipient faults [6]. In the spectrum analysis based fault diagnosis techniques [7], it is concluded that these faults are observable at some definite frequencies, which are different than the supply frequency. These stator winding faults are present due to several causes like inter-turn short circuit insulation failure [8], air gap eccentricity [9] etc; but not on account of degradation of stator groundwall insulation. The state of degradation of stator groundwall insulation of the respective phase results into the reduction of resistance to the thermal conductivity. This results into an increase in the rate of heat transfer from the surface of the stator winding conductors to the remaining part of the structure. This excessive heat loss to the surroundings is interpreted as the motor is subjected to excessive losses bearing the loss in efficiency at the supply frequency. Hence, motor draws more current as compared to what it would have drawn had the insulation not degraded. In view of the above reasons, the increase in current in respective phases leads to an unbalance in stator current at fundamental supply frequency.

The increase in current is accompanied as reduction in the steady-state equivalent resistance of motor referred to stator. The state of degradation of insulation of the respective phase, also results in the increase in the leakage current. This is on account of decrease in the magnetizing reactance (i.e., " $X_{m}$ ") component. The combined effect of the above two factors is interpreted as the reduction in the real part of the equivalent impedance of the motor referred to stator under the absence of mechanical load condition. The imaginary part of the equivalent impedance of the motor referred to stator under the absence of mechanical load condition will not change much since the inductance does not contribute to the dissipation of any energy on account of loss of heat to the surroundings. In the present work, as shown in the Fig.1 below, the reduction in the real part of an equivalent impedance of motor referred to stator under the absence of mechanical load condition (i.e., "Real (Zseq1_im_nl)") is simulated by the presence of suitable values of variable shunt resistance (i.e., " $R_{s h}$ ") connected across it in the lumped form.

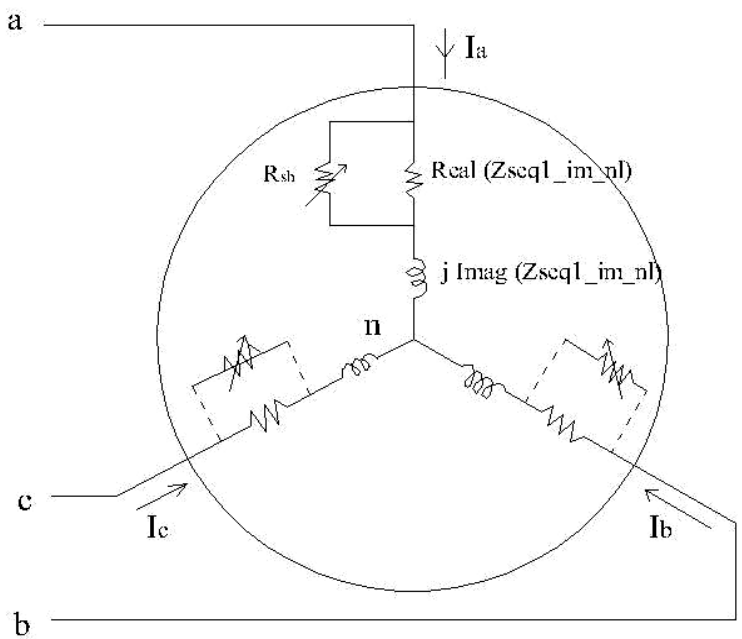

Fig. 1. Simulation of state of degradation of stator groundwall insulation of respective phase with isolated neutral

The computer simulation program is designed to generate unbalanced three-phase stator current data pattern on the basis of the resultant steady-state equivalent motor impedance per-phase. The resultant stator current data pattern is simulating the specific state of degradation of stator groundwall insulation of the respective phases of the motor under test. The computer simulation program incorporates the feature of extended park's transformation model to transform the three-phase unbalanced stator current data patterns in the three-phase ('abc') machine variable form into two-phase ('dq') park's current vector component form. The graphical representations of resultant park's current 'dq' data pattern forms are realized and illustrated. The computer simulation model is designed further to execute the extraction of various electrical variables and mathematical parameters, which specifically distinguish the state of degradation of stator groundwall insulation of respective phases. The detailed analysis and the summary of the series of extracted variables and mathematical parameters are presented for the particular case of the state of degradation of stator groundwall insulation.

\section{COMPuter Simulation MODEl FOR EVAluAtion OF STATE OF DEGRADATION OF STATOR GROUNDWALL INSULATION}

The simulation model is designed on the basis of certain reference conditions in context to the representation of balanced line voltages and the resulting unbalanced phase voltages and stator currents, over a phase plane.

\section{A. Nomenclature}

The nomenclature of various variables involved in the simulation model is detailed as under. The representation of 
the electrical variables over a phase plane is as shown in Fig. 2. The bold face symbolic representation of respective variables represents their corresponding RMS values.

$\mathrm{V}_{\mathrm{ab}}, \mathrm{V}_{\mathrm{bc}}, \mathrm{V}_{\mathrm{ca}}$ The absolute values of three-phase, balanced, line-to-line supply voltages, in 'Volts.'

$\mathrm{V}_{\mathrm{a}}, \mathrm{V}_{\mathrm{b}}, \mathrm{V}_{\mathrm{c}} \quad$ The absolute values of phase-voltages, in 'Volts.'

$\alpha_{a}, \alpha_{b}, \alpha_{c} \quad$ The phase angles of phase-voltages in electrical degrees (' ${ }^{\circ}$ ').

$\mathrm{I}_{\mathrm{a}}, \mathrm{I}_{\mathrm{b}}, \mathrm{I}_{\mathrm{c}} \quad$ The absolute values of stator current perphase, in 'Amps.'

$\beta_{\mathrm{a}}, \beta_{\mathrm{b}}, \beta_{\mathrm{c}} \quad$ The phase angles of phase-currents in electrical degrees ('०').

$Z_{a}, Z_{b}, Z_{c} \quad$ The absolute values of steady-state equivalent motor impedances per-phase refered to stator for the operation of motor under the absence of mechanical load condition corresponding to some finite values of shunt resistances (' $\mathrm{R}_{\mathrm{sh}}$ ').

$Z_{0} \quad$ The absolute value of steady-state equivalent motor impedance per-phase refered to stator for the operation of motor under the absence of mechanical load condition, for the value of shunt resistance (' $R_{\mathrm{sh}}$ ') equal to infinity $(\infty)$, in ohms (' $\Omega$ ').

$\mathrm{I}_{\mathrm{d}}, \mathrm{I}_{\mathrm{q}}, \mathrm{I}_{0}$ The absolute values of direct-axis, quadrature-axis, and zero-sequence current per-phase, in ('Amps.').

$\beta_{\mathrm{d}}, \beta_{\mathrm{q}} \quad$ The phase angles of 'direct-axis' and 'quadrature-axis' current, in electrical degrees ('o,).

$\mathrm{I}_{\mathrm{dq}} \quad$ The absolute value of resultant of the 'direct-axis' and 'quadrature-axis' current, in ('Amps.').

$\beta_{\mathrm{dq}} \quad$ The phase angle of resultant of 'direct-axis' and 'quadrature-axis' current, in electrical degrees (' ${ }^{\circ}$ ').

$\mathrm{L}_{\mathrm{MA}}, \mathrm{L}_{\mathrm{MB}}$, LR The length of major axis, length of minor axis, and latus rectum ('LR') of extended park's current data pattern, in ('Amps.').

$\varepsilon$ Eccentricity (' $\varepsilon$ ') of extended park's current data pattern.

$\theta_{0}^{\circ}, \theta_{\mathrm{m}}^{\circ} \quad$ Orientation angle and Angle of Major-axis of extended park's current data pattern (locus), in electrical degrees ( ${ }^{\circ} \circ$ ').

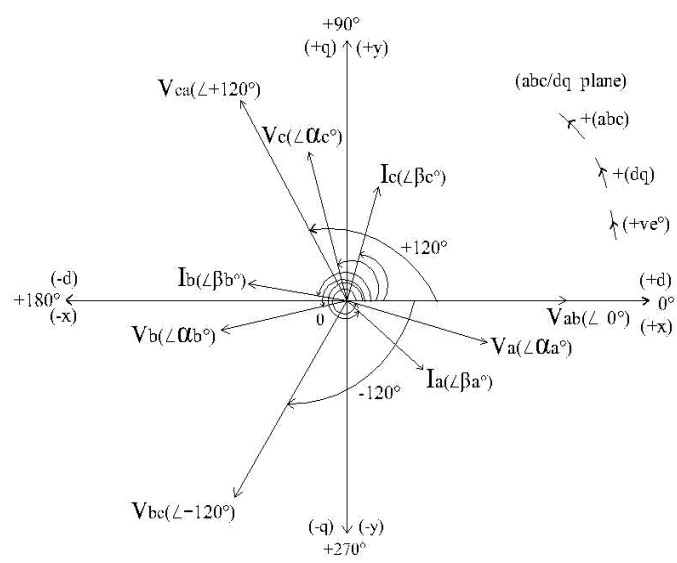

Fig. 2. Phase plane representation of electrical variables.
Simulation analysis is conducted on three-phase, 10HP (7.5-kW), star (Y)-connected, six-pole, induction motor. The steps involved for the evaluation of state of degradation of stator groundwall insulation are as under-

\section{B. Measurement of Induction Motor Machine Parameters}

The measurement of motor parameters is based on steady-state equivalent circuit of induction motor with the rotor at stator frequency as shown in the Fig. 3. The stator resistance test, no-load test, and locked rotor tests were conducted to measure the following motor parameters as shown below-

$\mathrm{R}_{\mathrm{s}}=$ Stator resistance per-phase $=0.1134 \Omega$.

$\mathrm{R}_{\mathrm{r}}=$ Rotor resistance per-phase referred to stator $=0.6808 \Omega$

$\mathrm{R}_{\mathrm{c}}=$ Core-loss resistance per-phase $=235.00 \Omega$

$\mathrm{X}_{\mathrm{ls}}=$ Stator leakage-reactance per-phase $=0.16 \Omega$.

$\mathrm{X}_{\mathrm{lr}}=$ Rotor leakage reactance per-phase referred to stator $=$ $0.16 \Omega$.

$\mathrm{X}_{\mathrm{m}}=$ Magnetizing mutual-reactance per-phase $=75.00 \Omega$.

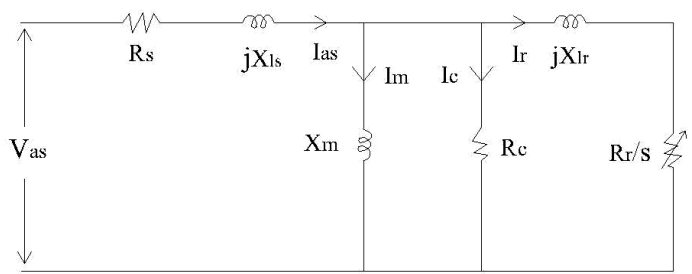

Fig. 3. Steady-state equivalent circuit of induction motor with rotor at stator frequency.

The measurement tests were performed at input power supply frequency of ' 50 ' $\mathrm{H}_{\mathrm{z}}$ and rated operating line voltage of '415.0' volts. The stator winding is star (Y) connected with isolated neutral and number of poles as ' 6 '.

\section{Performance Assessment of Motor by Steady-state Equivalent Circuit Model Simulation}

The computer simulation of steady-state equivalent circuit of induction motor with rotor at stator frequency is done on 'MATLAB.' The measured machine parameters are used to assess the performance of cage-rotor induction motor in the machine variable form under minimum mechanical load condition. The minimum mechanical load condition is realized under the absence of mechanical load, by decoupling the mechanical load from the shaft of motor. The numbers of computations involved in the evaluation of state of degradation of insulation are as under-

1) The computation of steady state performance of induction motor in machine variable form under minimum mechanical load condition.

2) Evaluation of maximum and minimum values of shunt resistances across the real part of equivalent steady state motor impedance per-phase referred to stator side at stator frequency under minimum mechanical load condition.

3) The computation of the numerical values of number of shunt resistances between maximum and minimum values, which are simulating different state of degradation of stator groundwall insulation.

4) The numbers of steady-state equivalent motor impedances per-phase refered to stator side (i.e., Zseq1_im_nl_xd) under the absence of mechanical load condition are computed for the range of values of shunt resistances (i.e., $\mathrm{R}_{\mathrm{sh}}$ ) within maximum and minimum values. 
The simulation results for the same computations are presented in Table I.

TABLE I: SimULATION Results OF STEADY-STATE Motor IMPEDANCES PER-PHASE

\begin{tabular}{|c|c|c|}
\hline $\begin{array}{c}\mathbf{R}_{\text {sh }} \\
(\mathbf{\Omega})\end{array}$ & $\begin{array}{c}\text { Percentage of Reduction } \\
\text { in Real Part of } \\
\text { (Zseq1_im_nl) (\%) }\end{array}$ & $\begin{array}{c}\text { Absolute Value of } \\
\text { Zseq1_im_nl_xd } \\
(\mathbf{\Omega})\end{array}$ \\
\hline$\infty$ & 0 & 36.7698 \\
\hline 608.1699 & 5 & 35.3853 \\
\hline 288.0805 & 10 & 34.0198 \\
\hline 96.0268 & 25 & 30.0627 \\
\hline 48.0134 & 40 & 26.3873 \\
\hline 32.0089 & 50 & 24.1575 \\
\hline 21.3393 & 60 & 22.167 \\
\hline 10.6696 & 75 & 19.7858 \\
\hline 3.5565 & 90 & 18.3763 \\
\hline 1.6847 & 95 & 18.166 \\
\hline
\end{tabular}

As shown in the 'Table-I,' the absolute value of steady-state motor impedance per-phase corresponding to an infinite $(\infty)$ value of shunt resistance $\left(R_{\text {sh }}\right)$, represents the healthy state of stator groundwall insulation of the respective phase. Similarly, the absolute value corresponding to some finite maximum value of shunt resistance (i.e., $608.1699 \Omega$ ) and minimum value of shunt resistance (i.e., $1.6847 \Omega$ ), represents a finite minimum and maximum (worst-case) state of degradation of stator groundwall insulation of the respective phase, respectively. The absolute value corresponding to the value of shunt resistance anything in between finite maximum and minimum value represents an arbitrary intermediate state of degradation of the respective phase. The numbers of combinations of these numerical values of steady state equivalent motor impedances per-phase refered to stator are determined to model the numbers of various states of degradation. The overall percentage of degradation (i.e., "per $x d(\%)$ ") is represented in numerical form by the concept of root mean square value of absolute deviation of impedances (i.e., " $Z \_x d(\Omega)$ ") in three phases. The same is now proposed with the following analytical definition.

$$
\begin{gathered}
Z_{-} x d=\left(\sqrt{\left(\left(Z_{0}-Z_{a}\right)^{2}+\left(Z_{0}-Z_{b}\right)^{2}+\left(Z_{0}-Z_{c}\right)^{2}\right) / 3}\right) \times 100 \\
\text { per_xd }(\%)=\left(\left(Z_{-} x d\right) /\left(Z_{0}\right)\right) \times 100
\end{gathered}
$$

The simple subroutine program is designed to determine numbers of such possible combinations for respective phases. These numbers of combinations of steady-state motor impedances per-phase are used further to compute the stator currents per-phase. The resulting unbalanced stator currents per-phase are computed under the condition of balanced supply voltage of star-(Y) connected stator winding with isolated neutral viz., (2) and (3).

$$
\begin{gathered}
V_{a b}+V_{b c}+V_{c a}=0 \\
I_{a}+I_{b}+I_{c}=0
\end{gathered}
$$

\section{Extended Park's Current Transformation Model for Computation of Direct-axis and Quadrature-axis Current Components}

The park's current vector pattern learning approach has been successfully applied in the fault diagnosis of ac induction motor drive [9]-[10]. In this investigation, the same approach is applied for the presentation of various states of degradation of insulation, occurring in respective phases of stator winding of induction motor. As shown in Fig. 4, the park's transformation model, transforms the presentation of unbalanced stator current data pattern in three-phase ('a-b-c') machine variable form into two-phase ('d-q') machine variable form over a phase-plane. For uniqueness of the transformation from one set of axes to another set of axes, including the unbalances in the 'abc' variables requires three variables such as 'dq0.' The relationship between 'dq0' and 'abc' current variables is derived as follows-

$$
\left[\begin{array}{c}
\boldsymbol{I}_{d} \\
\boldsymbol{I}_{q} \\
\boldsymbol{I}_{0}
\end{array}\right]=\frac{2}{3}\left[\begin{array}{ccc}
\cos \left(\beta_{a}^{\circ}\right) & \cos \left(\beta_{b}^{\circ}\right) & \cos \left(\beta_{c}^{\circ}\right) \\
\cos \left(\beta_{a}^{\circ}-90^{\circ}\right) & \cos \left(\beta_{b}^{\circ}-90^{\circ}\right) & \cos \left(\beta_{c}^{\circ}-90^{\circ}\right) \\
1 / 2 & 1 / 2 & 1 / 2
\end{array}\right]\left[\begin{array}{c}
\boldsymbol{I}_{a} \\
\boldsymbol{I}_{b} \\
\boldsymbol{I}_{c}
\end{array}\right]
$$

The zero sequence current ' $\mathbf{I}_{\mathbf{0}}$ ' (A) represents the imbalance in the 'phase-a, phase-b, and phase-c' currents. Under the practical condition of star (Y) connected stator winding with isolated neutral, the zero sequence current component is always equal to zero and does not produce the resultant magnetic field. The relationship between 'dq0' and 'abc' currents is modified as follows-

$$
\left[\begin{array}{c}
\boldsymbol{I}_{\boldsymbol{d}} \\
\boldsymbol{I}_{q}
\end{array}\right]=\frac{2}{3}\left[\begin{array}{ccc}
\cos \left(\beta_{a}^{\mathrm{o}}\right) & \cos \left(\beta_{b}^{\mathrm{o}}\right) & \cos \left(\beta_{c}^{\circ}\right) \\
\cos \left(\beta_{a}^{\mathrm{o}}-90^{\circ}\right) & \cos \left(\beta_{b}^{\circ}-90^{\circ}\right) & \cos \left(\beta_{c}^{\circ}-90^{\circ}\right)
\end{array}\right]\left[\begin{array}{c}
\boldsymbol{I}_{a} \\
\boldsymbol{I}_{b} \\
\boldsymbol{I}_{c}
\end{array}\right]
$$

The extended park's current transformation model detailed in (8) is included in computer simulation program to compute park's current data pattern for all possible combinations of unbalanced three-phase stator currents.

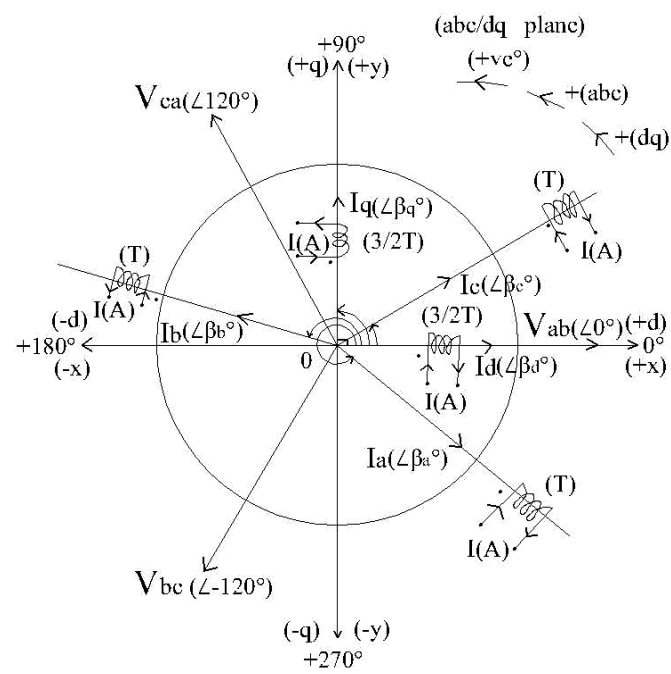

Fig. 4. Extended park's current transformation model. 
The simulation results of extended park's current data pattern, in equivalent two-phase 'dq' model form, for healthy state insulation present in any two-phases with variable state of degradation occurring in the remaining phase of induction motor under test are listed in 'Table-III.' The graphical representations of extended park's current data pattern are in an elliptic form. The computer program is designed further to extract certain mathematical parameters like length of major axis $\left(\mathrm{L}_{\mathrm{MA}}\right)$, length of minor axis $\left(\mathrm{L}_{\mathrm{MB}}\right)$, eccentricity $(\varepsilon)$, latus rectum (LR), angle of major axis $\left(\theta_{\mathrm{m}}{ }^{\circ}\right)$, and orientation angle $\left(\theta_{0}^{\circ}\right)$ of extended park's current data pattern (locus). The simulation results of extracted mathematical parameters are listed in 'Table-IV.' The extracted mathematical parameters are used to analyze and distinguish various states of degradation of stator groundwall insulation of respective phases for the induction motor under test. The performance analysis of the same is detailed with the support of graphical representations in the following sections.

The graphical representations of an extended park's current data pattern, for a particular class of equal variation in the state of degradation of insulation, occurring in all the three respective phases are in the circular form with centre at the origin over a dq-plane. The ideal condition refers to zero-percent $(0 \%)$ state of degradation of stator groundwall insulation, occurring in all the three respective phases. The associated electrical variables and extracted mathematical parameters for this state of reference are presented by the combination 'no.1' in the 'Table-II, Table-III, and Table-IV.' The extended park's current data pattern representation over a dq-plane is as illustrated in Fig. 5. The variations are observed with respect to circular extended park's current data pattern corresponding to combination'no.1' as a state of reference.

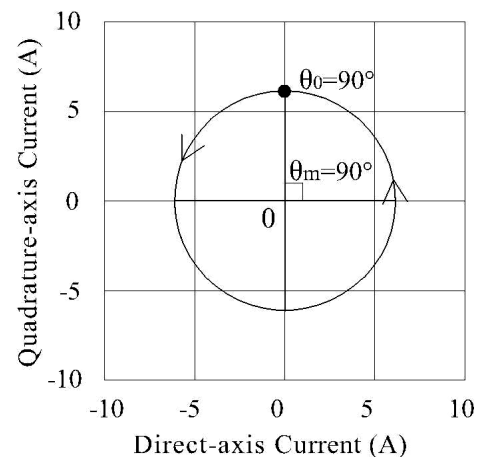

Fig. 5. Circular Current park's vector pattern as a reference data to simulate zero-percent state of degradation.

\section{Healthy State of Insulation Present In ANy} TwO-Phases With VARIABLE STATE OF DEGRADATION OF INSULATION IN REMAINING PHASE

The graphical representations of extended park's current data pattern for healthy state of insulation present in any two-phases with variable state of degradation of insulation, occurring in the remaining phase are in an elliptic form with centre at origin over a dq-plane. The magnitude of stator current per-phase corresponding to combination 'no. 1' under 'Table-II, Table-III, and Table-IV' is considered as reference value to represent the zero-percent $(0 \%)$ state of degradation of insulation of respective phase (i.e., a 'healthy state').

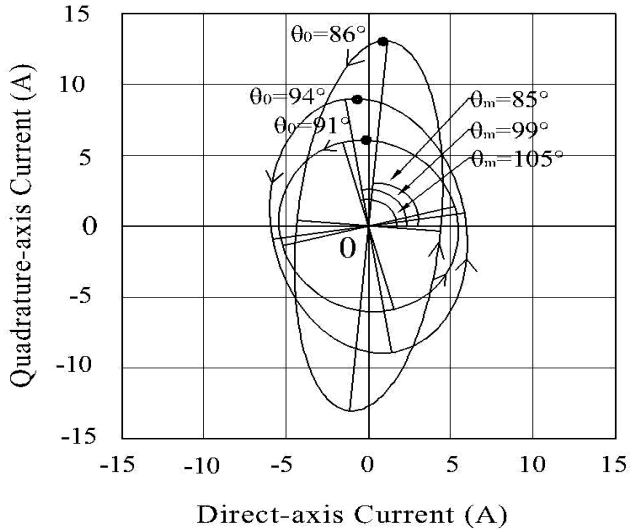

Fig. 6. Simulation of healthy State of Insulation in 'phase-b' and 'phase-c' with variable state of degradation in 'phase-a'

The performance analysis of electrical variables in three-phase machine model (a-b-c) form (refer 'Table-II'), equivalent two-phase model $(\mathrm{d}-\mathrm{q})$ form (refer 'Table-III'), and extracted mathematical parameters (refer 'Table-IV') for the variation in the state of degradation of insulation in 'phase-a' from healthy to worst-case state with healthy state of insulation present in 'phase-b' and 'phase-c' is presented in the 'Table-V.'

\section{A. Healthy State of Insulation in 'Phase-c' and 'Phase-a' with Variable State of Degradation in 'Phase- $b$ '}

The finite variation in the state of degradation of insulation in 'phase-b' with healthy state of insulation in 'phase-c' and 'phase-a,' will introduce the change in the shape of extended park's current data pattern from circular to elliptical form. As mentioned in an earlier 'case-A,' the simulation results of electrical variables and extracted mathematical parameters for the present 'case-B' are computed. On account of inadequate space, the simulated results are not shown in the present paper. However, the comparative performance analysis of the same is discussed and presented in the 'section-V.' It is imperative that, any variation in the state of degradation of insulation in 'phase-b' from healthy to worst-case state is always more than healthy state of insulation present in 'phase-c' and 'phase-a.' The graphical representations of selected no. of combinations (viz., '21, 201, and 381,' which are simulating ' $2.17 \%, 19.80 \%$, and $29.21 \%$ ' state of degradation of insulation, respectively) are presented in the Fig. 7.

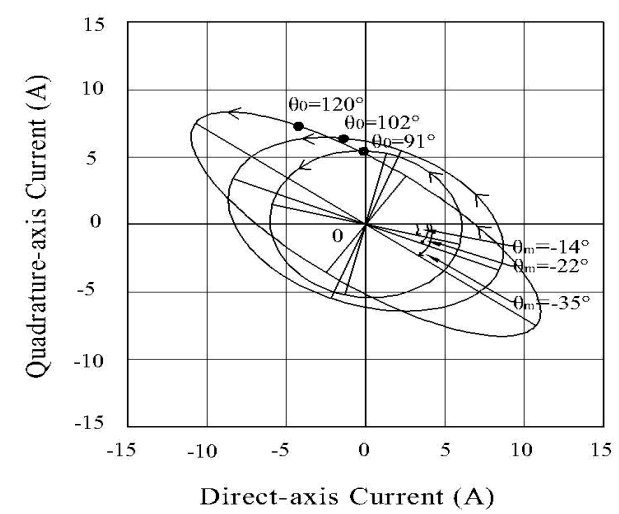

Fig. 7. Simulation of healthy state of insulation in 'phase-c' and 'phase-a' with variable state of degradation in 'phase-b' 


\section{B. Healthy State of Insulation in 'Phase- $a$ ' and 'Phase- $b$ '} with Variable State of Degradation in 'Phase-c'

The finite variation in the state of degradation of insulation in 'phase-c' with healthy state of insulation present in 'phase-a' and 'phase-b,' will introduce the change in the shape of extended park's current data pattern from circular to elliptical form. As mentioned in an earlier 'case-A,' the simulation results of electrical variables and extracted mathematical parameters for the present 'case-C' are computed.

On account of inadequate space, the simulated results are not shown in the present paper. However, the comparative performance analysis of the same is discussed and presented in the later 'section-V.' It is imperative that, any variation in the state of degradation of insulation in 'phase-c' from healthy to worst-case state is always more than healthy state of insulation present in 'phase-a' and 'phase-b'. The graphical representations of selected no. of combinations (viz., '2, 11, and 20,' which are simulating ' $2.17 \%, 19.80 \%$, and $29.21 \%$,' state of degradation of insulation, respectively) are presented in the Fig. 8 .

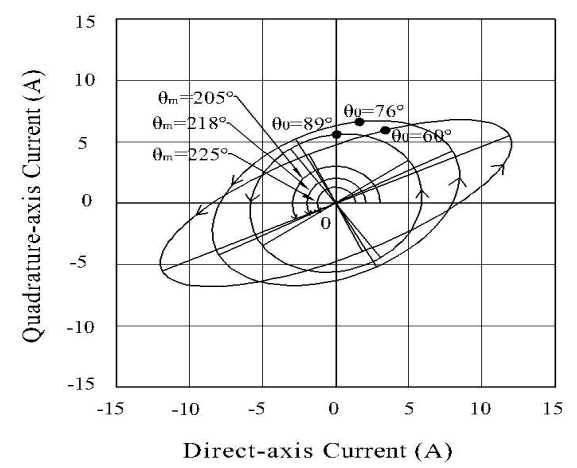

Fig. 8. Simulation of healthy state of insulation in 'phase-a' and 'phase-b' with variable state of degradation in 'phase-c'

\section{Discussion on Performance AnAlysis}

The progressive rise in an equal state of degradation of insulation (refer combination 'no. 1' in 'Table-II, Table-III, and Table-IV.') in all the three - phases results into the significant increase in the magnitudes of three-phase currents. Further, all the three-phase current phasors experiences a significant phase-shift in the clockwise direction but are still displaced in time with each other by $120^{\circ}$. In an equivalent two-phase (dq) model, the magnitudes of both direct-axis and quadrature-axis current significantly increases and are equal. However, there is no change in the phase-shift $\left({ }^{\prime} \beta_{\mathrm{d}}{ }^{\circ}=0\right.$ ' and $' \beta_{\mathrm{q}}=+90^{\circ}$ ') for either one of them. The magnitude of resultant dq-axis current $\left(\mathrm{I}_{\mathrm{dq}}\right)$ significantly increases whereas its phase-shift angle $\left(\beta_{\mathrm{dq}}{ }^{\circ}\right)$ does not experience any change and is at ' $+45^{\circ}$ ' with respect to reference. Hence, the extended park's current data pattern appears in the circular form with significant rise in its radius.

The healthy state of insulation present in any two-phases is always less dominant as compared to the progressive increase in the state of degradation of insulation from healthy to worst-case state in the remaining phase. If healthy state of insulation is present in any two-phases, and state of degradation of insulation, occurring in the remaining phase progressively increases from healthy to worst-case state (i.e., cases A, B, and C under 'section-IV') then the extended parks current data pattern appears in elliptic form. The magnitude of all the three phase currents $\left(I_{a}, I_{b}\right.$, and $\left.I_{c}\right)$ are different and they are not displaced in time with each other by $120^{\circ}$. The magnitude of current in an 'affected-phase,' experiences a significant increase in its value and varies from low to high range. The magnitude of current in the 'lagging-phase,' experiences a negligible decrease in its value and varies within a low range. The magnitude of current in the 'leadingphase,' experiences a moderate increase in its value and varies from low to medium range. In addition to an affected-phase, the lagging-phase current phasor experiences a moderate phase-shift in clockwise direction. The leading-phase current phasor experiences a negligible phase-shift in anti-clockwise direction.

The comparative performance analysis of simulated electrical variables in equivalent two-phase dq-model form is detailed in 'Table-VI.' The changes in magnitudes and phase-shift angles of direct-axis, quadrature-axis, and resultant dq-axis currents are varying over a different range to distinguish the presence of healthy state of insulation in any two-phases and variation in the state of degradation of insulation (from healthy to worst-case state) in the remaining phase.

The simulation results as shown in the figures 6,7 , and 8 , and the comparative performance analyses of corresponding simulated extracted parameters as detailed in 'Table-VII,' infers that the extracted parameter like angle of orientation $\left(\theta_{0}{ }^{\circ}\right)$ of an elliptic pattern (locus), changes its position over a variable range. It is changing over different zones (viz.,

' $+94.0^{\circ}$ to $+86.0^{\circ}$, $+90.0^{\circ}$ to $+120.0^{\circ}$, and $+60.0^{\circ}$, to $+90.0^{\circ}$ ') in a dq-plane, for healthy state of insulation present in any two-phases (viz., b-c, c-a, and a-b) and the variation in the state of degradation of insulation (from healthy to worst-case state), in the remaining affected-phase (viz., a, b, and c), respectively. This is illustrated in Fig. 9.

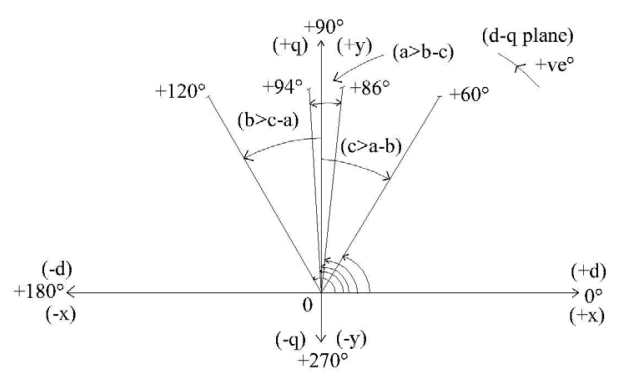

Fig. 9. Different zones of angle of orientation (' $\theta_{0}$ ') for healthy state of insulation in any two-phases and variation in the state of degradation of insulation in affected phase

In the following discussion, it is assumed that if the change in the value of stator current per-phase is within ' $25 \%$ ' of the reference value then the value of stator current per-phase is considered in the low range (L). Similarly, if the change in the value is from ' $25 \%$ ' to ' $60 \%$ ' of the reference value then the value of stator current per-phase is considered in the medium range $(\mathrm{M})$. Further, if the change in the value is above ' $60 \%$ ' of the reference value then the value of stator current per-phase is considered in the high range $(\mathrm{H})$.

The variations in the phase-shift displacements of electrical variables are measured with respect to reference with anticlockwise sense as positive. Any variation in phase-shift around and below ' $10^{\circ}$ ' in either direction is considered as negligible change in the phase-shift. Similarly, 
any variation in phase-shift from ' $10^{\circ}$ ' to ' $30^{\circ}$ ' in either direction is considered as moderate change in the phase-shift. Further, any variation in the phase-shift around and above ' $30^{\circ}$ ' in either direction is considered as significant change in the phase-shift. The variation in the phase-shift displacements of quadrature-axis current variable is measured with respect to positive q-axis (' $+90^{\circ}$ '), with anticlockwise sense as positive over a dq-plane as shown in the Fig. 4.

\section{A. Healthy State of Insulation in 'Phase- $b$ ' and 'Phase-c' with Variable State of Degradation in 'Phase- $a$ '}

The finite variation in the state of degradation of insulation in 'phase-a' with healthy state of insulation present in 'phase-b' and 'phase-c,' will introduce the change in the shape of extended park's current data pattern from circular to elliptical form. The simulation results in 'Table-II,' inferred that the magnitudes of all the three phase currents (i.e., $I_{a}, I_{b}$, and $I_{c}$ ) are different and they are not displaced in time with each other by $120^{\circ}$. Similarly, the simulation results in 'Table-III,' inferred that the magnitude of direct-axis current $\left(\mathrm{I}_{\mathrm{d}}\right)$ and quadrature-axis current $\left(\mathrm{I}_{\mathrm{q}}\right)$ are not equal and they are not displaced in time with each other by $90^{\circ}$. The resultant dq-axis current phasor $\left(\mathrm{I}_{\mathrm{dq}}\right)$ is not displaced in time by $'+45.0^{\circ}$ ' with respect to reference. The variations of electrical variables in either form are unlike in an equal variation in the state of degradation of insulation, in all the three respective phases. It is imperative that, any variation in the state of degradation of insulation in 'phase-a' from healthy to worst-case state is always more than healthy state of insulation present in 'phase-b' and 'phase-c.'

The graphical representations of extended park's current data pattern over a dq-plane for the selected number of combinations (viz., '401, 4001, and '7601,' which are simulating ' $2.17 \%, \quad 19.80 \%$, and $29.21 \%$ ' state of degradation of insulation, respectively) under 'Table-II, Table-III, and Table-IV' are presented in Fig. 6.

It is imperative that the variation in ' $\theta_{0}^{\circ}$ ' is symmetrical and limited over a moderate range with respect to positive 'q-axis' in context of a dominant progressive increase in the state of degradation of insulation (from healthy to worst-case state) in any one particular phase (viz., a, b, and c) and healthy state of insulation present in other two-phases (viz., b-c, c-a, and a-b), respectively. Similarly, the extracted parameter like angle of major-axis $\left(\theta_{\mathrm{m}}{ }^{\circ}\right)$ of an elliptic pattern, changes its position over a moderate range $\left(-20.0^{\circ}\right)$, which is identical irrespective of the healthy state of insulation present in any two-phases (viz., b-c, c-a, and a-b) and variation in the state of degradation of insulation (from healthy to worst-case state) in the remaining affected-phase (viz., a, b, and c), respectively. It is imperative that the variation in ' $\theta_{\mathrm{m}}{ }^{\circ}$ ' is symmetrically distributed by ' $120^{\circ}$ ' over distinct zones, in a dq-plane. The ' $\theta_{\mathrm{m}}{ }^{\circ}$ ' is changing over distinct zones (viz., ${ }^{\circ}+105.0^{\circ}$ to $+85.0^{\circ},-14.0^{\circ}$ to $-35.0^{\circ},+225.0^{\circ}$ to $+205.0^{\circ}$ ') in a dq-plane. This is illustrated in Fig. 10. It further suggests that these extracted parameters are sensitive within these specific limits.

With reference to 'Table-VIII,' it is observed that the changes in an extracted parameters like ' $\mathrm{L}_{\mathrm{MA}}, \mathrm{L}_{\mathrm{MB}}, \mathrm{LR}$, and $\varepsilon$ ' are identical, which occur irrespective of the healthy state of insulation present in any two-phases (viz., b-c, c-a, and a-b) and variation in the state of degradation of insulation (from healthy to worst-case state), in the remaining affected-phase (viz., a, b, and c), respectively. The identical changes in extracted parameters like ' $\mathrm{L}_{\mathrm{MA}}, \mathrm{L}_{\mathrm{MB}}$, and $\mathrm{LR}$ ' further suggests that the deformation in the shape of extended parks current elliptic pattern increases with the change in an eccentricity $(\varepsilon)$ from ' 0.2905 ' viz., close to zero (0) to ' 0.9411 ' viz., close to one (1).

The extracted parameter like eccentricity $(\varepsilon)$ is not sufficient to decide the level of state of degradation of insulation. In fact, it only suggests the deformation in the shape of extended park's current elliptic pattern and in turn suggests the degree of unbalance in the three phase stator current. The extracted parameter like length of major-axis $\left(\mathrm{L}_{\mathrm{MA}}\right)$, length of minor-axis $\left(\mathrm{L}_{\mathrm{MB}}\right)$, and latus rectum (LR) suggests the size of extended park's current elliptic pattern and in turn are sensitive to decide level of state of degradation of insulation. Hence, extracted parameters like ' $\mathrm{L}_{\mathrm{MA}}, \mathrm{L}_{\mathrm{MB}}$, $\mathrm{LR}$, and $\varepsilon$ ' are useful together to uniquely determine the qualitative level of variations (low, medium and high etc.) of progressive increase in the state of degradation of insulation in one particular phase with the presence of healthy state of insulation in other two-phases.

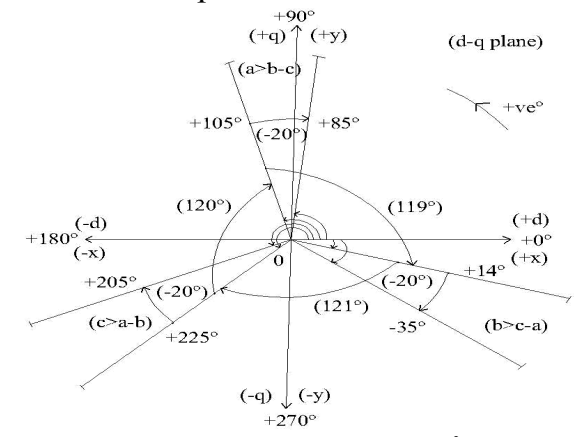

Fig. 10. Distinct zones of angle of major-axis $\left(\theta_{\mathrm{m}}{ }^{\circ}\right)$ for healthy state of insulation in any two-phases and variation in the state of degradation of insulation in affected phase

\section{CONCLUSIONS}

In the present work, the computer simulation model is developed to simulate arbitrary variations in the state of degradation of stator groundwall insulation, occurring in the respective phases of induction motor under test. An extended park's transformation model is used to transform the simulation results from three-phase ('a-b-c') model into a more convenient and simplified form of equivalent two-phase ('d-q') model over a dq-plane. Extended park's current data patterns are derived from two-phase ('d-q') model to distinguish the state of degradation of insulation. The performance evaluation of electrical variables and extracted parameters of extended park's current data patterns for particular case of progressive increase in the state of degradation of insulation, occurring in any one phase and healthy state of insulation present in remaining two-phases is presented. The performance evaluation of extracted features facilitates the appropriate selection of number of specific variables as input parameter conditions for the optimal design of suitable artificial intelligence (AI) based tool like artificial neural network classifier to distinguish the particular state of degradation of insulation. 
TABLE II: Simulation Results of Electrical Variables in Three-Phase Machine Model (ABC) Form For Healthy State of Insulation PRESEnt IN Phase-B AND Phase-C With VARiable State of Degradation In Phase-A.

\begin{tabular}{|c|c|c|c|c|c|c|c|c|c|c|}
\hline No. & $\begin{array}{c}\text { per_xd } \\
(\mathbf{\%})\end{array}$ & $\mathbf{Z}_{\mathbf{a}}(\mathbf{\Omega})$ & $\mathbf{Z}_{\mathbf{b}}(\mathbf{\Omega})$ & $\mathbf{Z}_{\mathbf{c}}(\mathbf{\Omega})$ & $\mathbf{I}_{\mathbf{a}}(\mathbf{A})$ & $\left.\boldsymbol{\beta}_{\mathbf{a}} \mathbf{(}^{(}\right)$ & $\mathbf{I}_{\mathbf{b}}(\mathbf{A})$ & $\left.\boldsymbol{\beta}_{\mathbf{b}} \mathbf{(}^{\circ}\right)$ & $\mathbf{I}_{\mathbf{c}}(\mathbf{A})$ & $\boldsymbol{\beta}_{\mathbf{c}}\left({ }^{\circ}\right)$ \\
\hline 1 & 0.00 & 36.7698 & 36.7698 & 36.7698 & 6.5162 & 300.519 & 6.5162 & 180.519 & 6.5162 & 60.5195 \\
\hline 401 & 2.1738 & 35.3853 & 36.7698 & 36.7698 & 6.6844 & 299.680 & 6.5164 & 179.666 & 6.6007 & 60.9364 \\
\hline 2001 & 10.5313 & 30.0627 & 36.7698 & 36.7698 & 7.4334 & 295.847 & 6.4995 & 175.772 & 7.0055 & 62.4427 \\
\hline 4201 & 16.3023 & 26.3873 & 36.7698 & 36.7698 & 8.0841 & 292.371 & 6.459 & 172.240 & 7.3926 & 63.2886 \\
\hline 4801 & 19.8034 & 24.1575 & 36.7698 & 36.7698 & 8.5637 & 289.702 & 6.4117 & 169.528 & 7.6974 & 63.6391 \\
\hline 6001 & 22.9290 & 22.167 & 36.7698 & 36.7698 & 9.0801 & 286.704 & 6.3421 & 166.480 & 8.0433 & 63.7582 \\
\hline 7601 & 29.6678 & 19.7858 & 36.7698 & 36.7698 & 9.9182 & 281.491 & 6.1798 & 161.176 & 8.6422 & 63.3716 \\
\hline
\end{tabular}

TABLE III: SimUlation Results of Electrical Variables in EQUivalent two-Phase Machine Model (DQ) Form For Healthy STATE OF

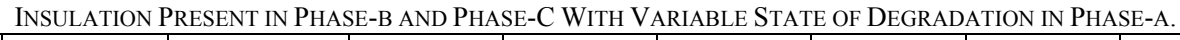

\begin{tabular}{|c|c|c|c|c|c|c|c|c|c|c|}
\hline No. & $\begin{array}{c}\text { per_xd } \\
(\mathbf{\%})\end{array}$ & $\mathbf{Z}_{\mathbf{a}}(\mathbf{\Omega})$ & $\mathbf{Z}_{\mathbf{b}}(\mathbf{\Omega})$ & $\mathbf{Z}_{\mathbf{c}}(\mathbf{\Omega})$ & $\mathbf{I}_{\mathbf{d}}(\mathbf{A})$ & $\boldsymbol{\beta}_{\mathbf{d}}\left({ }^{\circ}\right)$ & $\mathbf{I}_{\mathbf{q}}(\mathbf{A})$ & $\left.\boldsymbol{\beta}_{\mathbf{q}} \mathbf{(}^{\circ}\right)$ & $\mathbf{I}_{\mathbf{d q}}(\mathbf{A})$ & $\boldsymbol{\beta}_{\mathbf{d q}}\left({ }^{\circ}\right)$ \\
\hline 1 & 0.00 & 36.7698 & 36.7698 & 36.7698 & 6.5162 & 360 & 6.5162 & 90 & 9.2153 & 45 \\
\hline 401 & 2.1738 & 35.3853 & 36.7698 & 36.7698 & 6.4756 & 359.34 & 6.7262 & 90.629 & 9.2318 & 46.1002 \\
\hline 2001 & 10.5313 & 30.0627 & 36.7698 & 36.7698 & 6.2606 & 356.81 & 7.7158 & 92.5805 & 9.4356 & 51.2683 \\
\hline 4201 & 16.3023 & 26.3873 & 36.7698 & 36.7698 & 6.0243 & 355.29 & 8.6339 & 93.2802 & 9.8177 & 55.8593 \\
\hline 4801 & 19.8034 & 24.1575 & 36.7698 & 36.7698 & 5.8185 & 354.73 & 9.3366 & 93.2813 & 10.2407 & 59.0966 \\
\hline 6001 & 22.9290 & 22.167 & 36.7698 & 36.7698 & 5.568 & 354.83 & 10.1106 & 92.8403 & 10.8422 & 62.2729 \\
\hline 7601 & 29.6678 & 19.7858 & 36.7698 & 36.7698 & 5.1165 & 357.30 & 11.3852 & 91.2111 & 12.1599 & 66.3899 \\
\hline
\end{tabular}

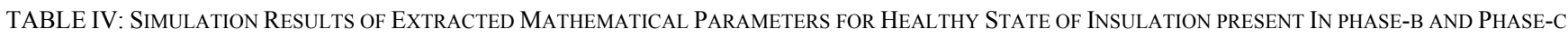

\begin{tabular}{|c|c|c|c|c|c|c|c|c|c|c|}
\hline No. & $\begin{array}{c}\text { per_xd } \\
\mathbf{( \% )}\end{array}$ & $\mathbf{Z}_{\mathbf{a}}(\mathbf{\Omega})$ & $\mathbf{Z}_{\mathbf{b}}(\mathbf{\Omega})$ & $\mathbf{Z}_{\mathbf{c}}(\mathbf{\Omega})$ & $\boldsymbol{\theta}_{\mathbf{0}}(\mathbf{})$ & $\boldsymbol{\theta}_{\mathbf{m}}(\mathbf{(})$ & $\mathbf{L}_{\mathbf{M A}}(\mathbf{A})$ & $\mathbf{L}_{\mathbf{M B}}(\mathbf{A})$ & $\boldsymbol{\varepsilon}$ & $\mathbf{L R}(\mathbf{A})$ \\
\hline 1 & 0.00 & 36.7698 & 36.7698 & 36.7698 & 90 & 90 & 13.0325 & 13.0325 & 0 & 13.0325 \\
\hline 401 & 2.1738 & 35.3853 & 36.7698 & 36.7698 & 90.629 & 104.4375 & 13.4918 & 12.9102 & 0.2905 & 12.3536 \\
\hline 2001 & 10.5313 & 30.0627 & 36.7698 & 36.7698 & 92.5805 & 102.6306 & 15.573 & 12.3448 & 0.6096 & 9.7858 \\
\hline 3201 & 16.3023 & 26.3873 & 36.7698 & 36.7698 & 93.2802 & 100.6544 & 17.4196 & 11.828 & 0.7341 & 8.0313 \\
\hline 4001 & 19.8034 & 24.1575 & 36.7698 & 36.7698 & 93.2813 & 98.776 & 18.8003 & 11.4305 & 0.7939 & 6.9496 \\
\hline 4801 & 22.9290 & 22.167 & 36.7698 & 36.7698 & 92.8403 & 95.7702 & 20.304 & 10.9846 & 0.841 & 5.9427 \\
\hline 6001 & 26.6678 & 19.7858 & 36.7698 & 36.7698 & 91.2111 & 92.0175 & 22.7834 & 10.2041 & 0.8941 & 4.5702 \\
\hline 7601 & 29.2111 & 18.166 & 36.7698 & 36.7698 & 86.9041 & 85.0749 & 26.3927 & 8.9307 & 0.941 & 3.022 \\
\hline
\end{tabular}

TABle V: Performance Analysis For Healthy State of Insulation Present in Phase-B and Phase-C With VARIABLe State OF Degradation in

\begin{tabular}{|c|c|}
\hline \multicolumn{2}{|r|}{ PHASE-A } \\
\hline $\begin{array}{l}\text { Extracted } \\
\text { Variable/ } \\
\text { Parameter }\end{array}$ & Performance Analysis \\
\hline $\mathrm{I}_{\mathrm{a}}, \mathrm{I}_{\mathrm{b}}, \mathrm{I}_{\mathrm{c}}$ & $\begin{array}{l}\text { The magnitude of current in an affected 'phase-a' experiences a significant increase from low to high range. The magnitude of } \\
\text { current in lagging 'phase-b' experiences a negligible decrease and varies within a low range. The magnitude of current in leading } \\
\text { 'phase-c' experiences a moderate increase and varies from low to medium range. }\end{array}$ \\
\hline$\beta_{\mathrm{a}}, \beta_{\mathrm{b}}, \beta_{\mathrm{c}}$ & $\begin{array}{l}\text { In addition to affected 'phase-a' the lagging 'phase-b' current phasor experiences moderate phase-shift in clockwise direction. The } \\
\text { leading 'phase-c' current phasor experiences negligible phase-shift in anti-clockwise direction. }\end{array}$ \\
\hline $\mathrm{I}_{\mathrm{d}}, \mathrm{I}_{\mathrm{q}}, \mathrm{I}_{\mathrm{dq}}$ & $\begin{array}{l}\text { ' } \mathrm{I}_{\mathrm{d}} \text { ' experiences a negligible decrease and varies within a low range. ' } \mathrm{I}_{\mathrm{q}} \text { ' experiences a significant increase and varies from low to } \\
\text { high range. ' } \mathrm{I}_{\mathrm{dq}} \text { ' experiences a significant increase and varies from low to high range. }\end{array}$ \\
\hline$\beta_{\mathrm{d}}, \beta_{\mathrm{q}}, \beta_{\mathrm{dq}}$ & $\begin{array}{l}\text { The ' } I_{d} \text { ' phasor experiences a negligible phase-shift in either direction while the ' } \mathrm{I}_{\mathrm{q}} \text { ' phasor experiences a negligible phase-shift in } \\
\text { opposite either direction. The ' } \mathrm{I}_{\mathrm{dq}} \text { ' phasor does have a moderate phase-shift in anticlockwise direction. }\end{array}$ \\
\hline$\theta_{0}{ }^{\circ}, \theta_{\mathrm{m}}{ }^{\circ}$ & $\begin{array}{l}\text { The ' } \theta_{0}{ }^{\circ} \text { ' changes its position over a negligible range }\left(+/-4.0^{\circ}\right) \text { in either direction with respect to positive q-axis. It is shifted from } \\
{ }^{\prime} \theta_{0}{ }^{\circ}=90^{\circ} \text { ' to ' } \theta_{0}^{\circ}=93.28^{\circ},\left(+94.0^{\circ}\right) \text { in anti-clockwise direction and then it is shifted back to some finite position ' } \theta_{0}^{\circ}=86.9041^{\prime} \\
\left(+86.0^{\circ}\right) \text { in clockwise direction with respect to reference. The ' } \theta_{\mathrm{m}}{ }^{\circ} \text { ' changes its position over a moderate range }\left(-20.0^{\circ}\right) \text { in clockwise } \\
\text { direction with respect to reference. It is shifted from ' } \theta_{\mathrm{m}}{ }^{\circ}=+104.4368^{\circ},\left(+105.0^{\circ}\right) \text { to ' } \theta_{\mathrm{m}}{ }^{\circ}=+85.0^{\circ} \text { ' }\left(+85.0^{\circ}\right) \text { in clockwise direction } \\
\text { with respect to reference. }\end{array}$ \\
\hline $\mathrm{L}_{\mathrm{MA},} \mathrm{L}_{\mathrm{MB}}$ & The ' $\mathrm{L}_{\mathrm{MA}}$ ' significantly increases (13.0325 to 26.3927) while ' $\mathrm{L}_{\mathrm{MB}}$ ' moderately decreases (13.0325 to 8.9307). \\
\hline LR & The 'LR' significantly decreases (13.0325 to 3.022) for a progressive rise in the state of degradation of insulation in 'phase-a.' \\
\hline$\varepsilon$ & $\begin{array}{l}\text { The deformation in an elliptic pattern changes with the variation in an eccentricity from } 0.2905 \text { (close to ' } 0 \text { ') to } 0.9410 \text { (close to ' } 1 \text { ') } \\
\text { for a progressive rise in the state of degradation of insulation in 'phase-a.' }\end{array}$ \\
\hline
\end{tabular}




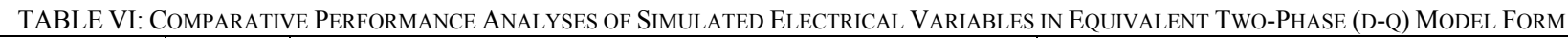

\begin{tabular}{|c|c|c|c|c|c|c|c|}
\hline \multirow{2}{*}{$\begin{array}{c}\text { Variation in } \\
\text { Degraded } \\
\text { Phase }\end{array}$} & \multirow{2}{*}{$\begin{array}{l}\text { Healthy } \\
\text { Phases }\end{array}$} & \multicolumn{3}{|c|}{ Magnitude of Currents (A) } & \multicolumn{3}{|c|}{ Phase Shift of Currents $\left({ }^{\circ}\right)$} \\
\hline & & $\mathbf{I}_{\mathrm{d}}(\mathrm{A})$ & $\mathbf{I}_{\mathrm{q}}(\mathrm{A})$ & $\mathbf{I}_{\mathrm{dq}}(\mathrm{A})$ & $\beta_{\mathrm{d}}\left({ }^{\circ}\right)$ & $\beta_{q}\left({ }^{\circ}\right)$ & $\beta_{\mathrm{dq}}\left({ }^{\circ}\right)$ \\
\hline $\begin{array}{c}a \\
(a>b-c)\end{array}$ & $b-c$ & $\begin{array}{c}(\mathrm{L}) \\
\text { Negligible } \\
\text { Decrease } \\
(6.51 \rightarrow 4.57)(\downarrow)\end{array}$ & $\begin{array}{c}(\mathrm{L} \text { to } \mathrm{H}) \\
\text { Significant } \\
\text { Increase } \\
(6.51 \rightarrow 13.51)(\uparrow)\end{array}$ & $\begin{array}{c}(\mathrm{L} \text { to } \mathrm{H}) \\
\text { Significant } \\
\text { Increase } \\
(9.21 \rightarrow 14.8) \quad(\uparrow)\end{array}$ & $\begin{array}{c}\text { Negligible } \\
\text { (either) } \\
\left(-6^{\circ} \rightarrow+9^{\circ}\right)\end{array}$ & $\begin{array}{c}\text { Negligible } \\
\text { (opposite } \\
\text { either) } \\
\left(+94^{\circ} \rightarrow+86^{\circ}\right)\end{array}$ & $\begin{array}{c}\text { Moderat } \\
\text { e } \\
\text { (anti- } \\
\text { clockwis } \\
\text { e) } \\
\left(+45^{\circ}\right. \\
\left.\rightarrow+70^{\circ}\right)\end{array}$ \\
\hline $\begin{array}{c}\mathrm{b} \\
(\mathrm{b}>\mathrm{c}-\mathrm{a})\end{array}$ & $\mathrm{c}-\mathrm{a}$ & $\begin{array}{c}(\mathrm{L} \text { to } \mathrm{H}) \\
\text { Significant } \\
\text { Increase } \\
(6.51 \rightarrow 11.14)(\uparrow)\end{array}$ & $\begin{array}{c}(\mathrm{L} \text { to } \mathrm{M}) \\
\text { Negligible } \\
\text { Dec. } / \text { Inc. } \quad(\downarrow \uparrow) \\
(6.51 \rightarrow 6.29 \rightarrow 8.35)\end{array}$ & $\begin{array}{c}(\mathrm{L}) \\
\text { Negligible } \\
\text { Inc. / Dec. }(\uparrow \downarrow) \\
(9.21 \rightarrow 9.27 \rightarrow \\
7.05)\end{array}$ & $\begin{array}{c}\text { Moderate } \\
\text { (clockwise) } \\
\left(0^{\circ} \rightarrow-22^{\circ}\right)\end{array}$ & $\begin{array}{c}\text { Significant } \\
\text { (anti-clockwise) } \\
\left(+90^{\circ} \rightarrow+120^{\circ}\right)\end{array}$ & $\begin{array}{c}\text { Moderat } \\
\text { e } \\
\text { (clockwi } \\
\text { se) } \\
\left(+45^{\circ}\right. \\
\left.\rightarrow+26^{\circ}\right) \\
\end{array}$ \\
\hline $\begin{array}{c}c \\
(c>a-b)\end{array}$ & $a-b$ & $\begin{array}{c}(\mathrm{L} \text { to } \mathrm{H}) \\
\text { Significant } \\
\text { Increase } \\
(6.51 \rightarrow 12.08)(\uparrow)\end{array}$ & $\begin{array}{c}(\mathrm{L}) \\
\text { Negligible } \\
\text { Inc. / Dec. } \quad(\uparrow \downarrow) \\
(6.51 \rightarrow 7.47 \rightarrow 6.93)\end{array}$ & $\begin{array}{c}(\mathrm{L} \text { to } \mathrm{H}) \\
\text { Significant } \\
\text { Increase } \\
(9.21 \rightarrow 17.7) \quad(\uparrow)\end{array}$ & $\begin{array}{c}\text { Moderate } \\
\text { (anti-clockwise) } \\
\left(+0^{\circ} \rightarrow 17^{\circ}\right)\end{array}$ & $\begin{array}{c}\text { Significant } \\
\text { (clockwise) } \\
\left(+90^{\circ} \rightarrow+60^{\circ}\right)\end{array}$ & $\begin{array}{c}\text { Negligibl } \\
\mathrm{e} \\
\text { (clockwi } \\
\text { se) } \\
\left(+45^{\circ}\right. \\
\left.\rightarrow+32^{\circ}\right)\end{array}$ \\
\hline
\end{tabular}

TABLE VII: EXTRACTED PARAMETERS ' $\Theta_{0}\left({ }^{\circ}\right)$ ' AND ‘ $\Theta_{\mathrm{M}}\left({ }^{\circ}\right)$ ’

\begin{tabular}{|c|c|c|c|c|c|}
\hline $\begin{array}{c}\text { Variation } \\
\text { in } \\
\text { Degraded } \\
\text { Phase }\end{array}$ & $\begin{array}{r}\text { Healthy } \\
\text { Phases }\end{array}$ & $\begin{array}{c}\text { Angle of } \\
\text { Orientation }\left(\theta_{0}{ }^{\circ}\right)\end{array}$ & $\begin{array}{l}\text { Range of Angle of } \\
\text { Orientation }\left(\theta_{0}{ }^{\circ}\right)\end{array}$ & $\begin{array}{l}\text { Angle of Major-Axis } \\
\qquad\left(\theta_{\mathrm{m}}{ }^{\mathrm{O}}\right)\end{array}$ & $\begin{array}{l}\text { Range of Angle of } \\
\text { Major-Axis }\left(\theta_{\mathrm{m}}{ }^{\circ}\right)\end{array}$ \\
\hline $\begin{array}{c}\mathrm{a} \\
(\mathrm{a}>\mathrm{b}-\mathrm{c})\end{array}$ & b-c & $\left(+94.0^{\circ}\right)$ to $\left(+86.0^{\circ}\right)$ & $\begin{array}{c}\text { Negligible } \\
(+/-4.0 \text { o }) \text { either way }\end{array}$ & $\left(+105.0^{\circ}\right)$ to $\left(+85.0^{\circ}\right)$ & $\begin{array}{l}\text { Moderate }\left(-20.0^{\circ}\right) \\
\text { clockwise }\end{array}$ \\
\hline $\begin{array}{c}\mathrm{b} \\
(\mathrm{b}>\mathrm{c}-\mathrm{a})\end{array}$ & $\mathrm{c}-\mathrm{a}$ & $\left(+90.0^{\circ}\right)$ to $\left(+120.0^{\circ}\right)$ & $\begin{array}{c}\text { Moderate } \\
(+30.0 \mathrm{o}) \text { anti-clockwise }\end{array}$ & $\left(-14.0^{\circ}\right)$ to $\left(-35.0^{\circ}\right)$ & $\begin{array}{l}\text { Moderate }\left(-21.0^{\circ}\right) \\
\text { clockwise }\end{array}$ \\
\hline $\begin{array}{c}c \\
(c>a-b)\end{array}$ & $a-b$ & $\left(+90.0^{\circ}\right)$ to $\left(+60.0^{\circ}\right)$ & $\begin{array}{c}\text { Moderate } \\
(-30.0 \mathrm{o}) \text { clockwise }\end{array}$ & $\left(+225.0^{\circ}\right)$ to $\left(+205.0^{\circ}\right)$ & $\begin{array}{l}\text { Moderate }\left(-20.0^{\circ}\right) \\
\text { clockwise }\end{array}$ \\
\hline
\end{tabular}

TABLE VIII: EXTRACTED PARAMETERS ' $\mathrm{L}_{\mathrm{MA}}, \mathrm{L}_{\mathrm{MB}}$, E, AND LR'

\begin{tabular}{|c|c|c|c|c|c|}
\hline $\begin{array}{l}\text { Variation } \\
\text { in } \\
\text { Degraded } \\
\text { Phase }\end{array}$ & $\begin{array}{l}\text { Healthy } \\
\text { Phases }\end{array}$ & Length of Major-Axis $\left(\mathrm{L}_{\mathrm{MA}}\right)$ & $\begin{array}{l}\text { Length of Minor-Axis } \\
\qquad\left(L_{M B}\right)\end{array}$ & Eccentricity $(\varepsilon)$ & Latus Rectum (LR) \\
\hline $\begin{array}{c}a \\
(a>b-c)\end{array}$ & b-c & $\begin{array}{l}\text { Significant Increase } \\
(13.0325 \rightarrow 26.3927) \quad(\uparrow)\end{array}$ & $\begin{array}{c}\text { Moderate Decrease } \\
(13.0325 \rightarrow 8.9307) \quad(\downarrow)\end{array}$ & $\begin{array}{l}0.2905 \text { (close to ' } 0 \text { ') } \\
\text { to } \\
0.9411 \text { (close to ' } 1 \text { ') }\end{array}$ & $\begin{array}{c}\text { Significant Decrease } \\
(13.0325 \rightarrow 3.022) \\
(\downarrow)\end{array}$ \\
\hline $\begin{array}{c}\mathrm{b} \\
(\mathrm{b}>\mathrm{c}-\mathrm{a})\end{array}$ & $\mathrm{c}-\mathrm{a}$ & $\begin{array}{c}\text { Significant Increase } \\
(13.0325 \rightarrow 26.3937)\end{array}$ & $\begin{array}{c}\text { Moderate Decrease } \\
(13.0325 \rightarrow 8.9278)(\downarrow)\end{array}$ & $\begin{array}{l}0.2905 \text { (close to ' } 0 \text { ') } \\
\text { to } \\
0.9411 \text { (close to ' } 1 \text { ') }\end{array}$ & $\begin{array}{c}\text { Significant Decrease } \\
(13.0325 \rightarrow 3.0199) \\
(\downarrow)\end{array}$ \\
\hline $\begin{array}{c}c \\
(c>a-b)\end{array}$ & $a-b$ & $\begin{array}{c}\text { Significant Increase } \\
(13.0325 \rightarrow 26.3945) \quad(\uparrow)\end{array}$ & $\begin{array}{c}\text { Moderate Decrease } \\
(13.0325 \rightarrow 8.9255) \quad(\downarrow)\end{array}$ & $\begin{array}{l}0.2905 \text { (close to ' } 0 \text { ') } \\
\text { to } \\
0.9411 \text { (close to ' } 1 \text { ') }\end{array}$ & $\begin{array}{c}\text { Significant } \\
\text { Decrease } \\
(13.0325 \rightarrow 3.0182) \\
(\downarrow)\end{array}$ \\
\hline
\end{tabular}




\section{REFERENCES}

[1] G. C. Stone, H. G. Sedding, B. A. Lloyd, and B. K. Gupta, "The ability of diagnostic tests to estimate the remaining life of stator insulation," IEEE Trans. on Energy Conversion, vol.3, no.4, pp. 833 - 841, Dec.1988.

[2] H. K. Yoshida, Umemoto, "Insulation Diagnosis for Rotating Machine Insulation," IEEE Trans. Electrical Insulation, vol. 21, no.6, pp. 1021-1025, Dec. 1986.

[3] T. Tsukui, M. Takamura, and Y. Kako, "Correlations between Nondestructive and Destructive Tests on High-Voltage Coil Insulations for Rotating Machines," IEEE Trans. Electrical Insulation, vol. 15, no. 2, pp. 118-124, April 1980.

[4] A. J. Modak and H. P. Inamdar, "Computer-Aided Characteristic Simulation Model of Deterioration of Insulation of Induction Motor," Proc. $3^{\text {rd }}$ IEEE Int. Conf. Computer and Electrical Engineering, IEEE Press, UESTC, Chengdu, China, Nov. 16-18 2010, vol.11, pp. VII-569-574. (ISBN: 978-1-4244-7224-6).2010.

[5] A. J. Modak and H. P. Inamdar, "Computer-aided Simulation Model of Stator Groundwall Insulation of Induction Motor based on Current Park's Vector Approach," Int. Journal of Computer Applications, Foundation of Computer Science, New York, USA. vol. 9, no. 8, pp. 24-33, Nov.2010. (ISBN: 978-93-80747-87-9).2010.

[6] S. Nandi and H. A. Toliyat, "Fault diagnosis of electrical machines-A review," in Proc. IEEE Int. Conf. Electric Machines and Drives, Seattle. WA, USA, May 9-12, 1999, pp. 219-221.1999.

[7] M. El. Hachemi Benbouzid, "Review of induction motor signature analysis as a medium for fault detection," IEEE Trans. Ind. Elect., vol.47, no.5, pp. 984-991, Oct.2000.

[8] F. C. Trutt et al, "Detection of AC machine winding deterioration using electrically excited vibrations," IEEE Trans. Ind. Applications, vol.17, no.1, pp. $10-13$, Jan. / Feb. 2001.

[9] A. J. M. Cardoso et al, "Computer aided detection of air gap eccentricity in operating three phase induction motors by Park's vector approach,” IEEE Trans. Ind. Applications, vol.29, pp. 897-901, Sept. / Oct. 1993.

[10] S. M. A. Cruz and A. J. M. Cardoso, "Rotor cage fault diagnosis in three-phase induction motors by Extended Parks Vector Approach," Elect. Mech. Power Syst., vol. 28, pp. 289-299, 2000.

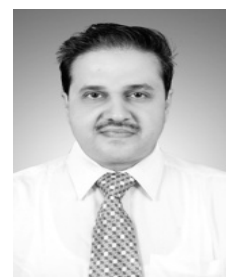

Amit J. Modak was born in Indore, India, on November 20, 1970. The author, graduated in (B.E.) Electrical Engineering from Visvesvaraya Regional College of Engineering, Nagpur, (Now, Visvesvaraya National Institute of Technology, Dimmed University, Nagpur), then affiliated to Nagpur University, India in 1992. The author, completed his post-graduation
(M.E.) in Electrical Engineering with the specialization in Control Systems Engineering from Walchand College of Engineering, Sangli affiliated to Shivaji University, Kolhapur, India in 2003. He hold a field experience of ' 5 ' years as a 'MAINTENANCE ENGINEER' in a continuous process steel industry and vast experience of about ' 10 ' years, as a 'LECTURER' and 'ASSISTANT PROFESSOR' in academic field. At present, He is registered for Ph. D. Program in Electrical Engineering with WCE, Sangli, at 'SHIVAJI UNIVERSITY,' Kolhapur, Maharashtra, India, His special field of interest included $\mathrm{AC} / \mathrm{DC}$ drive automation, artificial intelligence (AI) based fault diagnosis and monitoring techniques in context of simulation studies and hardware implementation of three-phase ac induction motors used in continues process industries. Mr. Modak is associated as a life member of Indian society for Technical Education, New Delhi, India Presented and published several number of research papers at various international conferences and journals.

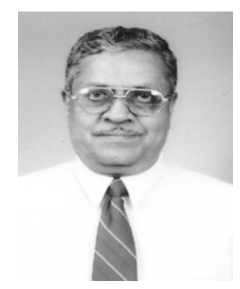

H. P. Inamdar was born in Sangli, India, on November 09, 1939. The author earned his B. Sc., from University of Pune, Pune, India. The author, obtained B. E. (Electrical Engineering) in 1964, B. E. (Mechanical Engineering) in 1965, and M.E. (Electrical Engineering) in 1975 from Shivaji University, Kolhapur, Maharashtra, India. The author received Ph. D. (High Voltage Engineering) in 1986 from Indian Institute of Science, Bangalore, India. His employment experience included as a 'PROFESSOR'

and 'HEAD' of electrical engineering department at Walchand College of Engineering, Sangli, India. At present, He is working as a 'RESEARCH PROFESSOR' in electrical engineering department at Rajarambapu Institute of Technology (autonomous institute), Rajaramnagar, District-Sangli, Maharashtra, India. He is associated as a Ph. D. research guide with Shivaji University, Kolhapur, India. He has a long experience of more than ' 45 ' years in academic and research field. He has done extensive research in the various fields of electrical engineering such as high voltage engineering, power system engineering, and biomedical engineering etc., He has published and presented more than ' 100 ' research papers in various national and international 'journals and conferences.' He also, authored number of text books in electrical engineering subjects. His previous and current field of interest included high voltage engineering and application of artificial intelligence (AI) based techniques in the domain of electrical and biomedical engineering.

Dr. Inamdar guided a number of students for 'Ph. D.' degree course and referee for 'Ph. D.' Thesis and Journal of Institutions of Engineers (India.) Dr. Inamdar worked for various research review committees and national board of accreditation, academic review committees for Shivaji University, Kolhapur, India and AICTE (India). Dr. Inamdar is associated as a life member of Indian society for Technical Education, New Delhi, India. 